\title{
Modernization of the General Reporting Framework for Accomplishing Corporate Governance Requirements
}

Bilal JIBAI ${ }^{1}$

\begin{abstract}
Corporate governance appears internationally as a concept that defines a leadership style of organizations, entities and even states, imposed by the wave of failures recorded in the work of large corporations. The unfavourable business affairs of large investors have affected the population as well as the investment environment as a whole. Large and recognized entities have suffered losses on the economic and financial area and especially in the image area, culminating in the necessity of imposing a new management style, but also a deeper and more serious control over all the functional links of those entities. Economic entities, as well as private organizations, are pursuing ways to operate efficiently, to invest in creating new jobs, to place themselves in good positions in capital markets, markets that give them the opportunity to enter in competition with other similar organizations. These goals can also be achieved when corporate governance is used as a management monitoring tool that can influence the behaviour of the organization as a whole. Under these conditions, corporate governance is the incentive to create a coherent investment environment and for the economic and social development of society.
\end{abstract}

Keywords: corporate governance, managerial process, economic performance, organizational behaviour, regulatory framework.

JEL classification: G30, G38, G40.

DOI: $10.24818 / \mathrm{RMCI}$.2018.3.252

\section{Introduction}

Corporate governance is a concept focused primarily on limiting the power of managers at the level of the entities they lead in line with promoting a stimulating investment climate. Even though corporate governance systems are generally different from one state to another, being strongly influenced by the level of development, perception and culture of the respective states, two identities can be identified that define this concept:

- Behavioural characteristic, which refers to the attitude, conduct and manner of action of the participants in the process of achieving the objectives included in the entity's strategy. These partners are: the leaders of the entity, the entire staff of the entity, the external collaborators and the state;

\footnotetext{
${ }^{1}$ The Bucharest University of Economic Studies, E-mail: bilaljibai@hotmail.com
} 
- Legislative characteristic, which covers the entire regulatory framework applicable to the specific activities carried out at the level of the entity in order to achieve in the optimal conditions the predefined performances.

Corporate governance has emerged as a necessity to ensure that the entity operates in the interests of shareholders and stakeholders (i.e. employees, business partners, managers, society as a whole). Therefore, there are two perspectives of corporate governance approach, namely (Harford et al., 2012):

- The shareholders model, according to which investors' interests must be fully realized;

- The stakeholders model according to which protecting the interests of many is a priority.

The condition for applying the shareholders model is the existence of strong capital markets in which the stock exchange activity is an efficient and certain one. Such cases are less common because it is difficult to meet the cumulative conditions required by the shareholders model. Instead, there are many cases of applying the stakeholders model, and the state is directly interested in supporting such a way of governance because it is socially beneficial. In this case, the state supports and enhances the application of the stakeholders model from which the benefits go to several social categories.

Satisfaction of investors' interests is to a large extent balanced with the added value that corporate governance can bring to the lives of all those interested in an economic entity: employees, management, collaborators, etc.

Also, the value added at the level of an economic entity is obtained by balancing the waiting levels of the categories of persons interested in the entity's activity, but also by avoiding conflicts of interest that may arise between the shareholder structure and the executive management of the entity.

While the benefits of the transparency of information on the real situation of economic entities are recognized, many of their leaders do not attach great importance to this, knowingly avoiding applying the rules of corporate governance. Good corporate governance can only develop if the business climate in the economy is stable and motivating (Davies, 2009). Therefore, corporate governance implemented at the level of the economic entities will achieve its expected performance levels if, at national level, the competent bodies take measures to balance the financial market and eliminate or adjust the causes of payment arrears in the economy (Bititci et al., 1997).

\section{The Influence of Information Provided by the Financial Statements on the Managerial Process}

The principles contained in codes of good practice in corporate governance are likely to highlight the quality and structure of information provided by financial statements. There are two fundamental criteria on the international level that can be used to estimate the level of implementation and development of corporate governance (Baker \& Barbu, 2007): 
- The rating received by the country in which the economic entity was established and it operates. This is reflected in the level of aid that the state grants to the respective economic entity so that it can implement and develop a corporate governance system capable of satisfying shareholders, directors, employees and employees alike. Some of the measures the state can promote in order to support the economic entities on their way to streamline their activities by implementing the principles of corporate governance are (Ali, 2005):

- adopting a legislative framework in the field of corporate governance;

- creating a regulatory framework regulating the capital market and making it accessible to entities and investors;

- the imposition of strict and unitary rules, which are applicable to all economic entities as regards the way of reporting the annual financial statements;

- strengthen control in respect of compliance with international financial reporting standards and the detection of those cases of breach of their provisions. the following:

- The rating the economic entity receives. This is made up of ratings for

- the shareholder structure that is no longer exclusively represented by the state;

- the degree of ensuring the transparency of the information provided by the financial statements;

- the level of appreciation of the collaboration with the stakeholders based on the degree of satisfaction of their needs by the economic entity;

- real independence of CEOs;

- healthy and accurate performance evaluation principles based on established targets;

- applying the principles, setting out the results, interpreting them, determining the level of deviation from pre-set targets, and dealing with deviations so that the next financial exercise completes with results as close as possible to what was predicted.

In order to provide a concrete and substantiated database for potential investors, the ratings should be summed up and the result interpreted over a period of several years so as to better target the decisions to invest the stakeholders. A maximum of the total of the two ratings, or a year-on-year increase in value, means an attractive investment opportunity for any potential investor. A year-to-year decline or even a stagnant result is interpreted by potential investors as a solution to be avoided or very carefully studied because it is not safe to invest in such an entity. If two economic entities have obtained the same rating, although they are operating in two different countries, investors will turn their attention to the economic entity in the country with a higher mark, precisely to certify that the 
environment in which the entity operates is very important, being a premise of future development.

The information contained in the financial reports is a source of significant influence on the decision-making process (Figure 1). The decision-making process is influenced by the quality of financial information. Poor quality information contained in the financial statements satisfies the minimum level of knowledge for the beneficiaries. They characterize economic entities whose leaders are not the followers of transparency, do not publish on their website the financial information, or do not own a website to promote the image of the entity. The decision-making process cannot even be based on this category of information.

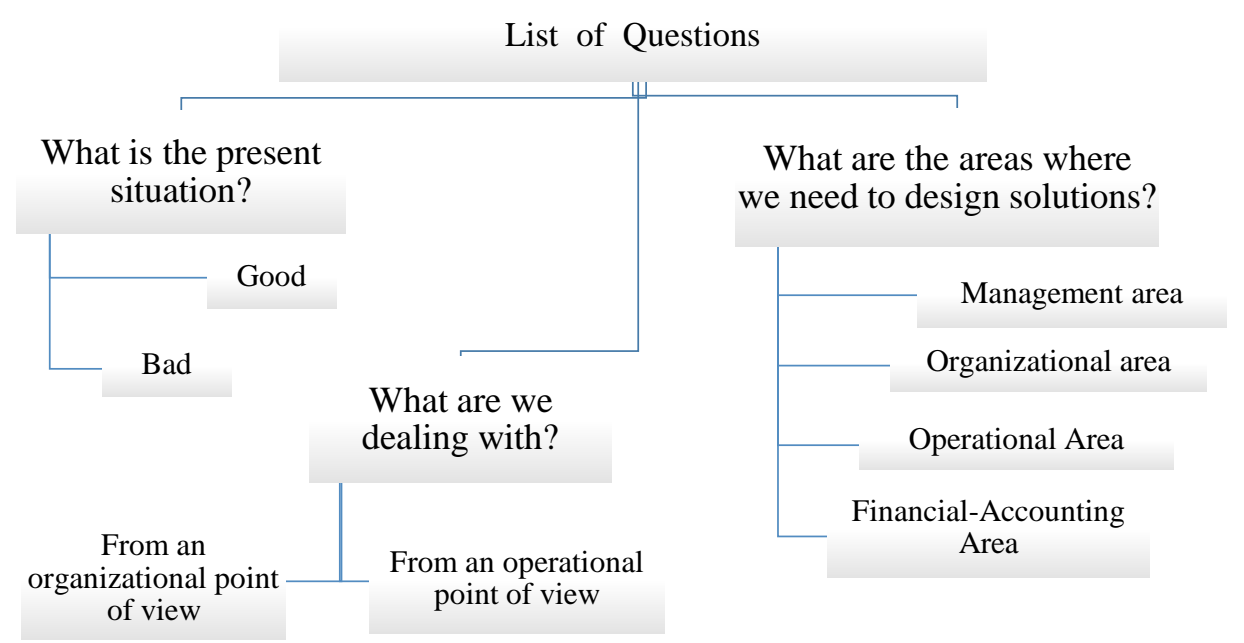

Figure 1. What aspects can financial information clarify?

Source: Created by author

Qualitatively acceptable information is published in a timely manner on the entity's own website. The decision-making process is based on this information but also needs additional data to make it satisfactory.

Good-quality financial information includes, in addition to financial statements, external, financial and / or statutory auditors' reports, as well as reports from directors. Such information through their quality, characterized by complexity, is useful in the decision making process providing a solid basis for targeting performance-oriented management actions and measures (Garrison et al., 2010). From the corporate governance context, economic entities that manage good quality financial information are more visible on the capital market, more attractive to prospective investors, and thus have sufficient data to make the decision to invest. The information contained in the financial statements can be considered as excellent when it is complete, developed according to all legal provisions in force, characterized by its sincerity and fairness, and especially reflecting how the entity has implemented and applies the principles of corporate governance. Obviously, 
such information has an important impact on decision-making. For good corporate governance, the information contained in the annual financial statements becomes basic, supportive and evolving elements. In support of this statement we list some of the characteristics of the information contained in the financial statements:

- It has a strong influence on the decision-making process at the level of an economic entity;

- It represents an efficient, useful and concrete source of information for all those interested in the economic situation of the economic entity in designing their own actions and attitudes towards the activity of the entity;

- It is a binder that connects all the other fields of activity of the economic entity and the economic and financial field, potentiating the information system implemented and developed within the economic entity.

The effects of information provided by financial statements on decisionmaking are also reflected in their ability to provide the appropriate solutions to the dilemmas faced by the different categories of beneficiaries of that information:

- Employees of the economic entity;

- Members of the governing bodies, such as the members of the Board of Directors (executive directors) and the members of the Board of Directors;

- The shareholders of the economic entity;

- Potential investors (shareholders);

- Collaborators, such as partner economic entities, state institutions, funding banks, etc.

There is an indissoluble link between the corporate governance process and the information provided by the annual financial statements, the two elements potentiating each other. Financial information is a permanent and controlled source of data on the basis of which the beneficiaries can successfully base their decisionmaking process. For any investor or shareholder of an economic entity, the main goal pursued is to satisfy its own interests, namely to bring profit to a maximum possible extent under the given conditions. Financial information comes to support this, being designated as key data for achieving performance-based, goal-driven and resultoriented management.

\section{Measuring the performance of the economic entity through the information contained in the financial statements}

The performance of the economic entity can be measured on the basis of the information contained in the financial statements. In this respect, the application of the principles of corporate governance has set out three perspectives on the basis of which an assessment can be made of the performances of the economic entity: 
Solvency $=$ the ability of the economic entity to pay its debt to a creditor at the predefined payment deadline.

Liquidity $=$ The ability of an enterprise to meet its short-term payment obligations by converting current assets into cash availability to make payments that become chargeable.

Profitability $=$ Financial result of an economic activity, materialized by the increase of the revenues from the expenses incurred and resulting in a value surplus called profit.

The information provided by the financial statements is a key element in the process of evaluating the performance of an economic entity, as well as the basis of a diagnosis of the factual state of the entity. On the basis of this information, it is possible to forecast future economic growth opportunities, to analyse the financial market stimuli to which the economic entity may react or to create investment plans that enhance the further development of the entity and position it favourably on the capital market.

\section{The performance of the economic entity - an essential element in the application of corporate governance}

Entity performance increases when corporate governance is welldeveloped at country level but also at the entity level, bringing added value to the capital market on which the entity is positioned. As a tool for increasing performance, corporate governance has the following influences on the entity:

- The importance given to the members of the Board of Directors is greatly increased;

- It is an incentive for strategic thinking and long-term design of the activity carried out within any economic entity;

- Creates a toolkit of utmost importance in the decision making process, setting the basis for an efficient control system with immediate effects on the organizational and functional plan of the economic entity;

- It is a basic element in targeting potential investors.

- At the level of the economic entities, performance can be assessed through a reference system consisting of performance indicators set for the objectives of the entity or for the activities undertaken to achieve them. In order to be able to analyse the achievement of the predetermined objectives of the entity of economic interest, it is necessary for each performance or output indicator to set targets, thresholds to be achieved in order for the activity to be considered as performing and the interests of investors / shareholders to be satisfied. In the context of corporate governance, performance measurement of specific activities becomes more a necessity than a desideratum or obligation. Performance review specialists have found that the intense concern of managers for this area has been able to boost the revision and improvement of financial reporting systems (Neely, 1999). 
Due to the organization, large-scale economic entities are more easily adaptable to corporate governance requirements. Achieving performance is unlike small business entities, it is easier for them to have a higher degree of credibility, they are senior in the field in which they have developed activities, they are trusted partners who have proved their seriousness and professionalism alongside the collaborations they have and have an advantageous position on the capital market on which they are quoted. The developed economic entities, which eventually also carry out monopoly activities in their field of activity, prefer to obtain financing from the capital market instead of financial institutions that can also provide development credits.

The existence of a regulatory framework for corporate governance can also be a reason to increase the bureaucratization of economic entities and stop the initiative of the team of executives who are forced to carry out those actions that will meet the wishes and expectations of the shareholders. An example of bureaucratisation is the following: legislation specific to corporate governance promotes the establishment of committees whose utility has not been fully substantiated, although it is undeniable that they may be useful. This, however, depends significantly on the degree of development of the economic entity and also on the organizational culture. Thus, committee-based management may be ineffective by the very fact that the relationship between the costs it generates is not in balance with the effects of the committees in the field of performance growth, strengthening financial discipline or ensuring transparency.

\section{Developing an organizational culture beneficial to the evolution of the economic entity}

Organizational culture represents all the standards of collective thinking, common attitudes, generally recognized values, accepted and respected norms that are used in an economic entity. Specialists who studied the concept claim that in order to achieve a high degree of competitiveness of the economic entity, organizational culture must be understood and respected by all employees, being adaptable to the development strategies it has established. The success of an economic entity closely linked to the organizational culture that exists within it that influences the behaviour of all employees, causing it to act in the interest of the economic entity but also for the own benefit and good of the entire community. Outstanding organizational cultures, built in time and adaptable to the demands of the environment in which the economic entity operates, evolve in the context of applying a set of techniques as follows:

- Developing and enforcing a Code of Conduct for employees of the economic entity in crisis situations, applicable both to decision-makers and staff who actually carry out their activities on execution positions. Given the existence of a code that regulates the behaviour of all employees, the managers' attitude is decisive for the entire staff, adapting to the needs of the entity;

258 Review of International Comparative Management Volume 19, Issue 3, July 2018 
- Creating a remuneration and reward system for employees who exceed the goals set for them in carrying out their own activities, contributing to the achievement of organizational performance;

- Recruiting appropriate people and promoting those employees who achieve the expected results, respecting the principles promoted within the economic entity, coupled with an effective system of individual performance assessments to identify the reasons that may lead to lack of performance, reasons that are later mitigated by appropriate measures;

- Strengthen employee trust in management and how it manages the decision-making system and internal control system. Moreover, employees' confidence in the possibilities of evolution of the economic and personal entities is a guarantee of an efficient organizational culture.

The performance of any economic entity is closely related to the professionalism and involvement of employees in its projects. Organizational culture thus becomes a difficult concept to define and harder to measure, interventions in its modelling being real challenges. Reporting financial results of economic entities must include relevant information, the form of which enables users to perform centralizations, analyses, evaluations and comparisons with similar entities (Brown \& Caylor, 2006). However, the high degree of relaxation of the legal framework regulating financial accounting activity creates the opportunity to use techniques that can negatively affect the reliability of the information provided. The implementation of the prudence principle and the lack of information on intangible assets give rise to the weaknesses that favour the distortion of financial accounting information (Edmonds et al., 2016).

\section{The influences of the financial statements in the area of increasing the viability of the economic entity}

The link between the information contained in the financial statements and the corporate governance lies in the very basic objective of the annual financial statements, namely to provide concrete data on the financial position, performance and cash flows of an economic entity useful for the entire list of users. In fact, financial statements are those tools that direct users to decisionmaking: regarding managerial, economic, or operational aspects, to invest, collaborate, etc. Based on financial results, shareholders are able to find out how the resource management available to administrators has been conducted in an economically, efficiently and effectively manner (Weygandt et al, 2015). In order to provide such information, the annual financial statements must include data on:

- Assets managed by the economic entity;

- The amount of the debts registered by the entity in the financial year ended;

- Owner-owned capital;

- The way of realizing the provisions of the budget of revenues and expenditures and especially the degree of budget execution; 
- The level of profit or loss recorded.

The performance reflected in the financial statements is based on the evolution of equity recorded during the financial year but excluding the operations of the direct interest entity with its shareholders. Therefore, the financial statements are a sound basis for estimating future cash flows by scoring the timing and certainty of cash generation in the next financial year.

In order to be useful and usable, the financial statements must be accurate, legally drawn up and timely disseminated in an appropriate manner. For economic entities, the annual financial statements are economic information and need to be made public so that they can be accessed by those interested. Transparency of financial statements ensures on one hand the information of their users and on the other hand their fairness. No leader of an economic entity should be negligent about the correctness of the information that is public, as this may have serious repercussions on it. Any economic entity is performing better as it is best managed.

Financial statements that define to a significant extent the performance of the entity are a basis for decision-making on current investors for the management of operations related to the invested capital. Thus, shareholders can decide in the following directions:

- To maintain further investment, in the short or long term;

- To increase the decision area by increasing the contribution to the capital;

- To reduce its capital by investing part of it in projects that are considered beneficial and necessary for the long-term development of the economic entity.

As the group of persons interested in the activity of the economic entity consists of several categories of persons, having different qualities compared to the economic entity, the financial statements reflect the performance by the way the results obtained meet the requirements of these categories of persons. Thus, performance can mean: maximizing profits for shareholders; advantageous and motivating salary packages for administrators; a balanced, stimulating, equitable work environment conducive to the initiative for employees or full satisfaction of needs for the community.

The main features of corporate governance through which it influences the viability and effectiveness of the entity are as follows:

- reflects the results and reliability of the functioning of the financial and accounting system;

- provides balance for the payments system;

- influences positively the real economy.

The opportunities to improve the performance of an economic entity lie in finding a balance between the four pillars on which it relies and increases:

- Efficiency of the production or service processes that are the subject of the entity's core business. This aspect has long been studied in specialized papers in the economic field, and the ways to achieve the goal are multiple. Among the most important, we mention the agreed objectives for setting up the economic entity and 
achieving the desired performance with the resources at its disposal. The process is not easy especially since on the one hand it is difficult to set some goals to meet fully the S.M.A.R.T. requirements in a context of constant change, and on the other hand it is difficult to adapt permanently from a limited resource flow;

- Satisfying shareholders' interests can be achieved by maximizing profits, their purpose being to receive the maximum possible in terms of capital investment. Achieving this goal is as challenging as difficult. The problem is that after investing, shareholders expect immediate results. However, it is difficult to predict what obstacles can occur in achieving activities and gaining profits, especially when the entity operates in an external environment that it cannot influence, but on the contrary it can affect its smooth and functioning activities aimed at obtaining profit. We point out that immediate profit should not be a measure of performance because it can be immediately followed by a sharp drop in results and a drastic reduction in future chances of evolution. In many cases, the profit achieved through small steps is safer and more stable. Understanding and applying these principles by shareholders can be the way to improve performance.

- Meeting the demand addressed to the services and products offered is also a measure of the performance of an economic entity. If we are talking about a market in which the entity positions itself as a monopoly, the performance, or rather the achievement of the expected results, is not an uncertainty. Instead, in a competitive market, with more bidders trying to meet customer requirements, things get complicated. Customer satisfaction becomes a complex issue for solving which must involve several sectors of the entity's own activity: marketing, quality management, staff upgrading, refurbishment. In order to adapt to market demand and achieve performance, an entity can reprogram it, trying to cover market segments that were not of interest until a certain point in time. However, this means giving up some segments that do not go or where the leadership position is held by other companies, but it also involves investing in means that help achieve the newly introduced goal. If the pre-investment studies are correct, clear, based on realities and substantiated forecasts, the entity's performance may improve considerably in the medium and long term.

- The ability of the economic entity to evolve, to record growth and to position itself on favourable market positions. Growth and development seen in the context of performance are defining elements. We cannot talk about an entity's overall performance if we exclude the development of activities, structural changes meant to cause the entity to adapt to changes coming from outside but also spent inside it, or to adapt to new legislative requirements, investment in upgrading, investment in human resources, performance support pillar, etc.

Other solutions to increase the performance of an economic entity are listed below, without claiming that we have fully covered the possibilities:

- Employing the staff of the entity and, most of all, staff from the key positions where the actions are directed, the results are assessed and the deviations from the established targets are established. Responsibility is achieved through official not verbal acts, as the latter have no effect. However, responsibility is not 
enough through job descriptions or by written orders of the head of the economic entity. It is essential to evaluate the performance gained from the accomplishment of the tasks and responsibilities set out. In fact, this is the measure of performance.

- Employee motivation is also a form of performance improvement. Establishing the overall economic entity's objectives, specific to each compartment in its organizational and individual structure, for each workstation is a first step in designing the system to facilitate performance. Setting the targets for the performance indicators attached to the objectives and for the result indicators attached to the activities leading to the objectives is the next step. Assessing the achievement of the set targets is a third step. Determining deviations from predetermined targets is an extremely relevant exercise in the process. However, recognizing the merits of those who have contributed to achieving or overtaking targets to delivering performance is a step in ensuring that it is improved in the future. From a psychological point of view, motivated employees work more efficiently and more responsibly, with their involvement at large odds. Staff whose merits are never reported or rewarded, do not have the same enthusiasm as this is detrimental to performance.

- Performance can be improved by changing the benchmark to which it relates. There are situations where economic entities relate to incorrectly established, outdated or preferential standards, for which the results are distorted. Improving performance is also based on setting appropriate, realistic landmarks that are strongly encoded in the realities of economic and social life.

\section{Conclusions}

In the context of a regulatory framework that is more or less avoided, the solution for the implementation of corporate governance consists in the methodological guidance and support of those who need counselling in the implementation process, in conjunction with the establishment of objective and independent controls by external bodies.

The success of applying the requirements of good practice codes in corporate governance can be achieved if the economic entity implements in a timely manner and just as the recommendations of external audits have been formulated, the objectives of which are directed towards assessing how the responsible persons fulfil the provisions in the field of corporate governance.

Improvements in the process of implementing corporate governance requirements may be recorded as a result of the implementation of the measures set by the tax authorities. Given the fact that the entities are on the pay list and are not up to date paying taxes and duties owed to the state budget, the step of stepping up tax controls is an additional argument for focusing the managers of the entities on the requirements of codes of good practice in corporate governance.

262 Review of International Comparative Management

Volume 19, Issue 3, July 2018 


\section{References}

Ali, M. J. (2005). A synthesis of empirical research on international accounting harmonization and compliance with international financial reporting standards. Journal of Accounting Literature, 24, 1.

Baker, C. R., \& Barbu, E. M. (2007). Trends in research on international accounting harmonization. The International Journal of Accounting, 42(3), 272-304.

Bititci, U. S., Carrie, A. S., \& McDevitt, L. (1997). Integrated performance measurement systems: a development guide. International journal of operations \& production management, 17(5), 522-534.

Brown, L. D., \& Caylor, M. L. (2006). Corporate governance and firm valuation. Journal of accounting and public policy, 25(4), 409-434.

Davies, M. (2009). Effective working relationships between audit committees and internal audit - the cornerstone of corporate governance in local authorities, a Welsh perspective. Journal of Management \& Governance, 13(1-2), 41-73.

Edmonds, T. P., Edmonds, C. D., Tsay, B. Y., \& Olds, P. R. (2016). Fundamental managerial accounting concepts. McGraw-Hill Education.

Garrison, R. H., Noreen, E. W., Brewer, P. C., \& McGowan, A. (2010). Managerial accounting. Issues in Accounting Education, 25(4), 792-793.

Harford, J., Mansi, S. A., \& Maxwell, W. F. (2012). Corporate governance and firm cash holdings in the US. In Corporate governance (pp. 107-138). Springer, Berlin, Heidelberg.

Neely, A. (1999). The performance measurement revolution: why now and what next?. International journal of operations \& production management, 19(2), 205-228.

Weygandt, J. J., Kimmel, P. D., \& Kieso, D. E. (2015). Financial \& managerial accounting. John Wiley \& Sons. 